\title{
COMUNICAÇÃOCIENTÍFICA \\ VARIAÇÃO SAZONAL DO ENRAIZAMENTO DE ESTACAS DE CULTIVARES DE Vitis rotundifolia ${ }^{1}$
}

\author{
SERGIO DENEGA ${ }^{2}$, LUIZ ANTONIO BIASI ${ }^{3}$, SIRLEI JANINE BLASKEVICZ ${ }^{4}$, FLÁVIO ZANETTE ${ }^{3}$
}

RESUMO - Este trabalho objetivou avaliar o enraizamento de 9 cultivares de Vitis rotundifolia nas quatro épocas do ano (verão, outono, inverno e primavera). As cultivares estudadas foram as seguintes: Topsail, Magnolia, Creek, Noble, Roanoke, Magoon, Regale, Bontiful e Dixie, sendo a estaquia realizada em câmara de nebulização intermitente, com o intervalo de rega controlado de acordo com a época do ano. O delineamento utilizado foi o inteiramente casualizado, com quatro repetições, nove tratamentos e 15 estacas por parcela. Todos os experimentos foram avaliados após 75 dias, levando-se em consideração as seguintes variáveis: porcentagem de estacas com folha e porcentagem de estacas enraizadas por parcela; número de raízes; comprimento $(\mathrm{cm})$ das raízes principais e massa seca das raízes por estaca $(\mathrm{mg})$. Nas estacas lenhosas, retiradas no outono e no inverno, não se obteve enraizamento. Com as estacas semilenhosas, retiradas no verão e na primavera, ocorreu enraizamento em todas as cultivares, com destaque para as cultivares Magnolia e Noble na primavera, que apresentaram $61,66 \%$ e 51,66\% de enraizamento, respectivamente. Nessa época, também ocorreu maior retenção foliar. A cultivar Bontiful demonstrou grande dificuldade de enraizamento. Para a propagação de cultivares de $V$. rotundifolia, recomenda-se a estaquia semilenhosa durante a primavera.

Termos para indexação: videira, estaquia, propagação.

\section{SEASONAL VARIATION OF ROOTING ON STEM CUTTINGS OF Vitis rotundifolia CULTIVARS}

ABSTRACT - The objective of this work was to evaluate the rooting on cuttings of nine Vitis rotundifolia cultivars during the seasons of the year (summer, autumn, winter and spring). The evaluated cultivars were: Topsail, Magnolia, Creek, Noble, Roanoke, Magoon, Regale, Bontiful e Dixie. The experiment was carried out under intermittent mist chamber, with irrigation controled according with the season of the year. The experimental design was in randomized blocks with nine treatments, each one with 4 replicates containing 15 stem cuttings. All experiments were evaluated after 75 days after planting and the following variables were determined: percentage of cuttings with leaf and percentage of rooted cutting per plot; number of roots, length $(\mathrm{cm})$ of main roots and dried mass of roots per cuttings. No roots developed on lignified cutings collected from plants during fall and winter. Cuttings collected from all cultivars during the summer and spring, were succesfully rooted, being superior on Magnolia and Noble cultivars during the spring, that showed $61.66 \%$ and $51.66 \%$ of rooting rate, respectively. This season also showed great leaf retention. The lowest percentage or rooting was observed for stem cuttings of the cultivar Bontiful. The resulst finally showed that spring is the best season for rooting of $V$. rotundifolia stem cuttings.

Index Terms: grape, cutting, propagation.

As estacas utilizadas para a propagação de porta-enxertos são normalmente coletadas durante o período de repouso da videira, quando as plantas estão sem folhas e com ramos maduros. Esse tipo de estaca lenhosa apresenta bons resultados de enraizamento para a maioria dos porta-enxertos utilizados comercialmente (Sousa, 1996; Pires \& Biasi, 2003). Entretanto, na propagação de cultivares de videiras muscadíneas (Vitis rotundifolia Michx.), as estacas lenhosas apresentam grande dificuldade de enraizamento, mesmo com a utilização de fitorreguladores (Cowart \& Savage, 1944; Goode Junior et al., 1982). A dificuldade de enraizamento é menor com a utilização de estacas semilenhosas com folhas mantidas em câmara de nebulização (Goode Junior \& Lane, 1983).

De acordo com Zuffellato-Ribas \& Rodrigues (2001), o enraizamento de estacas é influenciado pela auxina, embora esta não seja a única substância envolvida. Na estaquia, a auxina natural, produzida nas folhas e nas gemas, move-se naturalmente para a parte inferior da planta, aumentando a sua concentração na base do corte, junto com os açúcares e outras substâncias nutritivas. A época do ano em que é realizada a estaquia é fator importante para o enraizamento dos porta-enxertos. O efeito da época de estaquia, está relacionado com a condição fisiológica da planta-matriz e a lignificação dos ramos no momento de sua coleta (Hartmann et al., 2002).

O presente trabalho teve como objetivo observar o enraizamento de nove cultivares da espécie $V$. rotundifolia em quatro épocas do ano.

Este experimento foi conduzido em casa de vegetação do

\footnotetext{
${ }^{1}$ (Trabalho 092-06). Recebido em 06-07-2006. Aceito para publicação em : 02-03-2007. Parte da Tese de Doutorado do primeiro autor apresentada ao Programa de Pós-Graduação em Agronomia - Produção Vegetal da Universidade Federal do Paraná. Curitiba - PR.

${ }^{2} \mathrm{Eng}^{\circ} \mathrm{Agr}^{\circ} \mathrm{MSc} . /$ Economista, Departamento de Agronomia, UNICENTRO. E-mail: sdenega@unicentro.br. Rua Simeão Camargo Varela de Sá, ${ }^{\circ}$ 03. Bairro Cascavel, CEP 85.065-090 - Guarapuava - PR.

${ }^{3} \mathrm{Eng}^{\circ} \mathrm{Agr}^{\circ}$, Dr. Professor. Departamento de Fitotecnia e Fitossanitarismo. Universidade Federal do Paraná. Caixa Postal 19061. CEP 81.531-990.

Curitiba - PR. Bolsista de Produtividade em Pesquisa do CNPq.

${ }^{4}$ Aluna do Curso de Agronomia da UFPR. Bolsista de Iniciação Científica do CNPq.
} 
Departamento de Fitotecnia e Fitossanitarismo da UFPR, em Curitiba-PR. O material vegetal foi coletado da coleção de cultivares de V. rotundifolia, implantada em julho de 1999, com mudas provenientes da Embrapa Uva e Vinho (CNPUV), existentes no Setor de Fruticultura da Estação Experimental do Canguiri da UFPR, em Pinhais-PR.

As cultivares de $V$. rotundifolia estudadas foram as seguintes: Topsail, Magnolia, Creek, Noble, Roanoke, Magoon, Regale, Bontiful e Dixie. A estaquia foi realizada em quatro épocas do ano de 2004: final do verão, final do outono, final do inverno e final da primavera. $\mathrm{O}$ delineamento adotado foi o inteiramente casualizado, com quatro repetições, nove tratamentos e 15 estacas por parcela, sendo que o período das avaliações foi de março/ 2004 a janeiro/2005.

Nas épocas de primavera e verão, as estacas tinham consistência semilenhosa e foram mantidas com uma folha inteira na gema superior. Nas épocas de outono e inverno, as estacas tinham consistência lenhosa e não possuíam folhas. As estacas foram preparadas do terço médio e basal dos ramos, com $10 \mathrm{~cm}$ de comprimento e diâmetro entre 0,3 e $0,5 \mathrm{~cm}$, possuindo uma ou mais gemas, dependendo do comprimento dos entrenós. $\mathrm{O}$ substrato empregado foi a vermiculita, colocada em bandejas plásticas perfuradas com dimensões de $65 \times 44 \times 19 \mathrm{~cm}$, comportando quatro repetições em cada uma delas, mantidas em câmara de nebulização intermitente, com o intervalo de rega controlado de acordo com a época do ano.

Após 75 dias da estaquia, em todas as épocas, as seguintes variáveis foram avaliadas: porcentagem de estacas com folha e porcentagem de estacas enraizadas por parcela; número de raízes, pressupostos de homocedasticidade (Teste de Bartlett) e de normalidade dos resíduos para realizar a análise de variância. Quando não atenderam, foram utilizados os testes nãoparamétricos de Kruskal-Wallis e o teste da Mediana. Quando os pressupostos foram atendidos, as médias dos tratamentos foram comparadas pelo teste de Tukey.

As estacas semilenhosas da primavera foram as que apresentaram maior porcentagem de enraizamento, destacandose as cultivares Magnólia e Noble, com $61,66 \%$ e 51,66\%, respectivamente (Tabela 1). Resultados semelhantes também haviam sido obtidos por Biasi \& Boszczowski (2005), com estacas semilenhosas da cultivar Magnólia, que apresentou $63 \%$ de enraizamento, concluindo que a produção de mudas pode ser obtida pela estaquia semilenhosa sem o uso de auxinas. Botelho et al. (2005), que trabalharam com estacas lenhosas, semilenhosas e herbáceas do porta-enxerto de videira '43-43', híbrido de $V$. rotundifolia com $V$. vinifera L., obtiveram a melhor resposta de enraizamento com a estaquia herbácea realizada em janeiro, sem o uso de reguladores de crescimento, atingindo $92 \%$ de enraizamento, enquanto as estacas lenhosas não enraizaram. Esse fato também foi observado com o caquizeiro, que apresentou enraizamento apenas com a utilização de estacas herbáceas, em comparação com estacas lenhosas (Bastos et al., 2005). Na primavera, a cultivar Bontiful apresentou a menor porcentagem de enraizamento $(3,33 \%)$, não diferindo significativamente das cultivares Creek e Magoon com 19,99 e 19,98\%, respectivamente.
No período de verão, não houve diferença estatística significativa entre as cultivares para a porcentagem de enraizamento. No outono e no inverno, não ocorreu formação de raízes, com exceção de uma estaca da cultivar Noble (Tabela 1), concordando com o trabalho apresentado por Sharpe (1954), em que as estacas de ramos semilenhosos foram consideradas de maior habilidade de enraizamento do que as de ramos lenhosos. Esse resultado também confirma o já observado por Goode Júnior \& Lane (1983), onde as estacas semilenhosas com folha apresentaram maior facilidade de formação de raízes do que as lenhosas, principalmente em cultivares de difícil enraizamento, como as da espécie Vitis rotundifolia. Os mesmos autores verificaram, ainda, que a consistência dos ramos também afeta o enraizamento, que é prejudicado quando se utilizam as partes apicais muito tenras ou as porções basais com maturidade avançada.

Não houve diferença significativa quanto à retenção foliar após 75 dias em casa de vegetação na estação da primavera. Por outro lado, na época de verão, as cultivares Noble, Regale e Bontiful apresentaram as menores taxas de retenção foliar e, por conseqüência, também as menores taxas de enraizamento (Tabela 1). Essa relação comprova a importância da presença das folhas nas estacas, que funcionam como um laboratório de produção de hormônios e nutrientes, que são translocados para a base da estaca (Hartmann et al., 2002). Reuveni \& Raviv (1981) afirmaram que a contribuição das folhas no processo de enraizamento é explicada pela continuação do processo de fotossíntese, que leva à produção de carboidratos e sua acumulação na base das estacas, além de auxinas.

A baixa taxa de enraizamento obtida com algumas cultivares talvez possa ser elevada com o tratamento das estacas com auxina para favorecer a formação de raízes. Entretanto, a resposta à aplicação de reguladores de crescimento não é totalmente segura, pois, na propagação de cultivares de videiras muscadíneas ( $V$. rotundifolia) com estacas lenhosas, elas apresentam grande dificuldade de enraizamento, mesmo com a utilização de reguladores de crescimento (Cowart \& Savage, 1944). As auxinas não são as únicas substâncias necessárias para a indução de raízes em estacas, sendo importante um equilíbrio com outras substâncias, denominadas co-fatores de enraizamento, que podem favorecer ou prejudicar o enraizamento (Hartmann et al., 2002).

O crescimento das raízes, para a maioria das cultivares, foi maior na primavera do que no verão, como se pode observar para o comprimento (Tabela 1) e massa seca das raízes (Tabela 2). Na primavera, não houve diferença significativa para o comprimento das raízes formadas entre as cultivares. No verão, a cultivar Magnólia destacou-se, com $6,81 \mathrm{~cm}$ de raízes, sendo superior às cultivares Noble, Regale e Magoon, e não diferindo das demais (Tabela 1).

Quanto ao número de raízes emitidas por estaca, na primavera, houve uma grande uniformidade entre as cultivares com a formação de aproximadamente 2 raízes por estaca, com exceção da cultivar Bontiful que apresentou o menor número médio 
$(0,5)$. No verão, ocorreu maior diferença entre as cultivares, com destaque para Dixie (4,41), Magnólia (4,02), Topsail $(3,57)$, Roanoke $(2,93)$ e Creek $(1,70)$ que apresentaram o maior número de raízes e foram estatisticamente semelhantes (Tabela 2).

Para a variável massa seca de raízes por estaca, na primavera, não houve diferença significativa entre as cultivares. Por sua vez, no verão, as cultivares Dixie $(64,4 \mathrm{mg})$, Magnólia (37,6mg), Topsail (31,7mg), Roanoke (20,5mg) e Creek (17,5mg) foram superiores às demais (Tabela 2). A massa seca também foi maior na primavera do que no verão, fato que deve estar associado aos tecidos das estacas serem mais jovens e estarem em maior atividade do que no verão, produzindo maior quantidade de fotoassimilados e hormônios necessários para o crescimento das raízes.

Para a propagação de cultivares de $V$. rotundifolia, recomenda-se a estaquia semilenhosa durante a primavera. Entretanto, ainda são necessários estudos mais profundos com a utilização de reguladores de crescimento e outras técnicas, como o estiolamento de ramos, como forma de estimular a indução radicial.

TABELA 1 - Porcentagem de estacas enraizadas, porcentagem de estacas com folha e comprimento das raízes emitidas por estaca de nove cultivares de Vitis rotundifolia avaliadas após 75 dias, nas quatro épocas do ano. Curitiba-PR, 2004

\begin{tabular}{|c|c|c|c|c|c|c|c|c|c|c|c|c|}
\hline \multirow[t]{2}{*}{ Cultivar } & \multicolumn{4}{|c|}{ Estacas enraizadas (\%) } & \multicolumn{4}{|c|}{ Estacas com folhas (\%) } & \multicolumn{4}{|c|}{ Comprimento das raízes/estaca $(\mathrm{cm})$} \\
\hline & OUT & INV & PRI & VER & OUT & INV & PRI & VER & OUT & INV & PRI & VER \\
\hline Topsail & 0,00 & 0,00 & $31,66 b^{1}$ & $31,66 \mathrm{a}^{1}$ & - & - & $73,33 \mathrm{a}^{2}$ & $34,99 \mathrm{ab}^{1}$ & - & - & $9,39^{\mathrm{ns}}$ & $5,15 \mathrm{abc}^{\mathrm{I}}$ \\
\hline Magnólia & 0,00 & 0,00 & $61,66 \mathrm{a}$ & 21,66 a & - & - & $90,00 \mathrm{a}$ & $33,33 \mathrm{ab}$ & - & - & 8,14 & $6,81 \mathrm{a}$ \\
\hline Roanoke & 0,00 & 0,00 & $29,99 \mathrm{~b}$ & $18,32 \mathrm{a}$ & - & - & $65,00 \mathrm{a}$ & $19,99 \mathrm{abc}$ & - & - & 9,90 & $5,57 \mathrm{ab}$ \\
\hline Magoon & 0,00 & 0,00 & $19,98 \mathrm{bc}$ & $18,33 \mathrm{a}$ & - & - & $6,67 \mathrm{a}$ & $11,66 \mathrm{abc}$ & - & - & 8,25 & $0,00 \mathrm{c}$ \\
\hline Creek & 0,00 & 0,00 & 19,99 bc & 26,66 a & - & - & $20,00 \mathrm{a}$ & 34,99 abc & - & - & 10,19 & 3,37 abc \\
\hline Regale & 0,00 & 0,00 & $21,66 \mathrm{~b}$ & $4,99 \mathrm{a}$ & - & - & $55,00 \mathrm{a}$ & $6,66 \mathrm{bc}$ & - & - & 8,50 & $0,55 \mathrm{bc}$ \\
\hline Dixie & 0,00 & 0,00 & $28,32 \mathrm{~b}$ & 29,99 a & - & - & $36,66 \mathrm{a}$ & $54,99 \mathrm{a}$ & - & - & 5,89 & $3,67 \mathrm{abc}$ \\
\hline Noble & 0,00 & 1,66 & $51,66 \mathrm{a}$ & $1,66 \mathrm{a}$ & - & - & $70,00 \mathrm{a}$ & $0,00 \mathrm{c}$ & - & 5,58 & 14,72 & $0,00 \mathrm{c}$ \\
\hline Bontiful & 0,00 & 0,00 & $3,33 \mathrm{c}$ & $1,66 \mathrm{a}$ & - & - & $6,66 \mathrm{a}$ & $5,00 \mathrm{bc}$ & - & - & 6,52 & $2,02 \mathrm{abc}$ \\
\hline C.V. $(\%)$ & - & - & 68,5 & 108,4 & - & - & 66,9 & 57,1 & - & - & 51,8 & 102,3 \\
\hline
\end{tabular}

OUT = outono; INV = inverno; PRI = primavera; VER = verão.

${ }^{1}$ Médias seguidas pela mesma letra na coluna não diferem significativamente, pelo Teste de Tukey, a 5\% de probabilidade.

${ }^{2}$ Médias seguidas pela mesma letra na coluna não diferem significativamente, pelo Teste de Mediana não-paramétrico, a $5 \%$ de probabilidade.

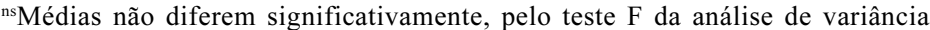

TABELA 2 - Número e massa seca de raízes emitidas por estaca de nove cultivares de Vitis rotundifolia avaliadas após 75 dias, nas quatro épocas do ano. Curitiba-PR, 2004

\begin{tabular}{|c|c|c|c|c|c|c|c|c|}
\hline \multirow[t]{2}{*}{ Cultivar } & \multicolumn{4}{|c|}{ Número de raízes/estaca } & \multicolumn{4}{|c|}{ Massa seca de raízes/estaca (mg) } \\
\hline & OUT & INV & PRI & VER & OUT & INV & PRI & VER \\
\hline Topsail & - & - & $1,25 \mathrm{ab}^{1}$ & $3,57 \mathrm{ab}^{1}$ & - & - & $49,2 \mathrm{a}^{2}$ & $31,7 \mathrm{a}^{1}$ \\
\hline Magnólia & - & - & $1,92 \mathrm{ab}$ & $4,02 \mathrm{ab}$ & - & - & 34,5 a & 37,6 a \\
\hline Roanoke & - & - & $1,94 \mathrm{ab}$ & 2,93 abc & - & - & 57,9 a & $20,5 \mathrm{a}$ \\
\hline Magoon & - & - & $2,62 \mathrm{a}$ & $0,00 \mathrm{c}$ & - & - & $97,0 \mathrm{a}$ & $0,0 \mathrm{c}$ \\
\hline Creek & - & - & $2,80 \mathrm{a}$ & $1,70 \mathrm{abc}$ & - & - & $66,1 \mathrm{a}$ & $17,5 \mathrm{ab}$ \\
\hline Regale & - & - & $2,35 \mathrm{a}$ & $0,50 \mathrm{c}$ & - & - & $51,2 \mathrm{a}$ & $0,0 \mathrm{c}$ \\
\hline Dixie & - & - & $2,06 \mathrm{ab}$ & $4,41 \mathrm{a}$ & - & - & 18,5 a & $64,4 \mathrm{a}$ \\
\hline Noble & - & 1,08 & $2,05 \mathrm{ab}$ & $0,25 \mathrm{c}$ & - & - & $62,7 \mathrm{a}$ & $0,0 \mathrm{c}$ \\
\hline Bontiful & - & - & $0,50 \mathrm{~b}$ & $1,25 \mathrm{bc}$ & - & - & $25,5 \mathrm{a}$ & $12,5 \mathrm{bc}$ \\
\hline C.V. (\%) & - & - & 48,9 & 94,9 & - & - & 85,7 & 150,9 \\
\hline
\end{tabular}

OUT = outono; INV = inverno; PRI = primavera; VER = verão

${ }^{1}$ Médias seguidas pela mesma letra na coluna não diferem significativamente, pelo teste de Tukey, a 5\% de probabilidade.

${ }^{2}$ Médias não diferem significativamente, pelo teste não-paramétrico Kruskal-Wallis.

\section{REFERÊNCIAS}

BASTOS, D.C.; PIO, R.Ç SCARPARE FILHO, J.A.; LIBARDI, M.N.; ALMEIDA, L.F.P.; ENTELMANN, F.A. Enraizamento de estacas lenhosas e herbáceas de cultivares de caquizeiro com diferentes concentrações de ácido indolbutírico. Revista Brasileira de Fruticultura, Jaboticabal, v. 27, n.1, p. 182184. 2005.

BIASI, L.A.; BOSZCZOWSKI, B. Propagação por estacas semilenhosas de Vitis rotundifolia cvs. Magnólia e Topsail. Revista Brasileira de Agrociência, Pelotas, v.11, n.4, p.405407, 2005.
BOTELHO, R.V.; MAIA, A.J.; PIRES, E.J.P.; TERRA, M.M.; SCHUCK, E. Efeitos de reguladores vegetais na propagação vegetativa do porta-enxerto de videira '43-43'(Vitis viniferax $V$. rotundifolia). Revista Brasileira de Fruticultura, Jaboticabal, v.27, n.1, p.6-8, 2005.

COWART, F.F.; SAVAGE, E.F. The effect of various treatments and methods of handling upon rooting of muscadine grape cuttings. Proceedings of the American Society for Horticultural Science, Alexandria, v. 44, p. 312-314. 1944.

GOODE JUNIOR, D.Z.; LANE, R.P. Rooting leafy muscadine grape cuttings. HortScience, Alexandria, v. 18, n. 6, p. 944-946. 1983. GOODE JUNIOR, D.Z.; KREWER, G.W.; LANE, R.P.; DANIELL, 
J.W.; COUVILlON, G.A. Rooting studies of dormant muscadine grape cuttings. HortScience, Alexandria, v. 17, n. 4, p. 644-645. 1982.

HARTMANN, H.T.; KESTER, D.E.; DAVIES JUNIOR, F.T. Plant propagation: principles and practices. $7^{\text {th }}$ ed. Englewood Cliffs: Prentice Hall, 2002. 880p.

PIRES, E.J.P.; BIASI, L.A. Propagação da videira. In: POMMER, C.V. Uva: tecnologia de produção, pós-colheita, mercado. Porto Alegre: Cinco Continentes, 2003. p.295-350.

REUVENI, O.; RAVIV, M. Importance of leaf retention to rooting of avocado cuttings. Journal of the American Society for Horticultural Science, Alexandria, v. 106, n. 2, p. 127-130. 1981.

SHARPE, R.H. Rooting of muscadine grapes under mist. Proceedings of the American Society for Horticultural Science, Alexandria, v. 63, p. 88-90. 1954.

SOUSA, J.S.I. de. Uvas para o Brasil. Piracicaba: FEALQ, 1996. $791 \mathrm{p}$.

ZUFFELLATO-RIBAS, K.C.; RODRIGUES, J.D. Estaquia: uma abordagem dos principais aspectos fisiológicos. Curitiba: UFPR, 2001.39p. 